\title{
MANAGING HUMANITARIAN EMERGENCIES Teaching and Learning with a Virtual Humanitarian Disaster Tool
}

\author{
Olatokunbo Ajinomoh, Lisa Dow, Alan Miller, Alasdair Gordon-Gibson and Eleanor Burt \\ School of Computer Science, School of Management, University of St Andrews, St Andrews, Scotland \\ \{oa224, lisa.dow, alan.miller,agg2,eb19\}@st.andrews.ac.uk
}

Keywords: Virtual Worlds: Humanitarian Emergencies: Collaborative Learning: Scenario-Based Training.

Abstract: The importance of specialist intervention in the form of humanitarian aid from governments, NGOs and other aid agencies during a humanitarian emergency cannot be over-emphasised. Humanitarian aid is the assistance provided in response to a humanitarian crisis. Humanitarian aid may be logistical, financial or material and its central aim is to alleviate human suffering and save lives. This paper describes an interdisciplinary project that created the Virtual Humanitarian Disaster learning and teaching resource (VHD) that is centred on the events occurring in the aftermath of an earthquake. To facilitate learning, scenarios with integrated task dilemmas have been modelled which will provide the opportunity for users of the resource to explore the inter-relationships between the key areas of activities which are important to the NGOs and other bodies which deliver humanitarian aid. Such areas include geo-political relationships, legal and regulatory requirements, information management, logistic, financial and human resource management imperatives. The VHD is primarily aimed at students. It creates a more flexible learning and teaching environment when compared with traditional classroom methods. The resource enables students to make decisions concerning critical situations within the controlled environment of a virtual world, where the consequences of any wrong decisions, will not directly impact on lives and property. The VHD has been embedded within an undergraduate module of the School of Management as it specifically relates to the final thematic area within which the module engages, namely the strategic and operational challenges faced by NGOs operating in the "humanitarian relief industry". We demonstrate that virtual worlds can be used to enhance learning and make it more engaging. The VHD affords students the opportunity to explore given scenarios in accordance with a specified budget and in so doing, they realise module outcomes in a more active and authentic learning environment.

\section{INTRODUCTION}

In the event of a humanitarian disaster or emergency, there are several groups of people responsible for managing the sudden influx of displaced populations and providing immediate aid. One such group is humanitarian aid agencies.

As a result of new and evolving standards and guidelines, changing donor roles, challenges in accessing populations in need, chronic conflicts and irregular climate patterns which have left communities more vulnerable than ever. Humanitarian aid operations have become increasingly complex and exposed the need to grow a pool of well-trained humanitarian professionals.

This paper discusses the rationale for, and describes the process involved in, the creation of the Virtual Humanitarian Disaster (VHD) resource and how it is relates to the subject of humanitarian assistance. Both areas are examined further in the following sections. The technical and educational platforms that support the VHD are detailed in Section two. Section three describes the VHD design and specific features, while section four documents the evaluation process.

\subsection{Refugees and Humanitarian Aid}

The 1951 UN Convention's defines a refugee as: "Any person who owing to well-founded fear of being persecuted for reasons of race, religion, nationality, membership of a particular social group or political opinion, is outside the country of his nationality and is unable, or owing to fear is unwilling to avail himself of the protection of that country; or who, not having a nationality and being outside the country of his former habitual residence, 
is unable, or having such fear is unwilling to return to it" (UNHCR, 2011).

This definition has been revised since 1951 with many amendments and recommendations on the status of refugees (D'Souza, 2007). The term refugee is sometimes used to describe internally displaced populations who fall outside of the legal definition of the convention. In a number of cases, people affected by disasters do not become refugees but are internally displaced. Displaced populations leave their homes in groups, usually due to a sudden impact, such as an earthquake or a flood, threat or conflict and there is usually an intention to return home (IFRC, 2011).

Humanitarian aid has been described as consisting of a series of tasks such as improving living conditions, providing basic care and support to affected populations in humanitarian emergency areas (Beristain, 2006). It has also been described as a professional discipline with the noble goals of helping fellow human beings to alleviate hunger and pain, giving succour to starving and homeless people, re-uniting ruptured families and rebuilding destroyed societies (Cahill, 2003).

\subsection{Learning in Virtual Worlds}

The humanitarian emergency report (DFID, 2011) highlighted the fact that well trained and experienced personnel are a major factor in successful humanitarian disaster response. The VHD enables simulation based training to inform students about the dilemmas aid workers encounter on the job.

The term simulation-based training refers to a collection of training methods, which are aimed at bridging the gap between classroom knowledge and actual practice, by placing the learner in a realistic situation within a context in which the individual is forced to bring to bear prior knowledge and make decisions to solve the problem. This method of training offers an immersive experience for the learner and provides an opportunity to evaluate and reflect upon their decisions. The advantage here when compared with on the job training lies in the fact that any decisions made in the course of the simulation would not have any effects beyond the simulation, as opposed to a real world situation where such decisions may have far reaching consequences which impact on human lives.

Humanitarian aid training is predominantly classroom-based, and the completion of a classroombased course alone, does not necessarily equip personnel for complex humanitarian operations where they may be left overwhelmed and barely able to cope in real deployments.

Humanitarian aid teams deployed in emergencies are often required to initiate rapid assessments and implement appropriate interventions within days of a humanitarian emergency. Coupled with a need for a rapid response in conditions of extreme physical and mental stress, the aid workers must adapt to and deal with unfamiliar demographics, cultures, political environments and climates. This further complicates the task of implementing relief activities that are timely and well organised.

Teaching within virtual worlds using the VHD provides a new approach for learning where conventional e-learning and blended learning cannot easily reach. There are benefits when using virtual worlds in education, either as a supplementary resource or as the main platform for teaching. The main benefits are; enriched interaction whereby face to face communication is replicated more closely than in other mediums and users are allowed to replicate body language and gestures (Grondstedt, 2008), increased speed of decision making when users work together on a challenge in groups (Heiphetz, 2010). Other benefits include; better conceptual demonstrations on complex scientific concepts, rich content engagement for learning, higher learning autonomy for students and facilitating collaborations between physically remote students. (Perera et al, 2009).

In summary, skills that were relevant a decade ago are insufficient to ensure success in today's complex humanitarian relief environment. For this reason, there is need for a new approach to training and skills development in the humanitarian aid industry.

\section{THE TECHNOLOGY}

There are several 3D environments available such as World of Warcraft, Blue Mars, IMVU, MOOVE, Active Worlds and Second Life. These 3D environments can be categorised as either Massive Multiplayer Online Role Playing Games (MMORPG) or Multi User Virtual Environment (MUVE). A MUVE provides an intuitive 3D environment where users are represented by avatars. This presence is engaging users are able to, and like interacting with each other. This in turn provides natural support for group work and collaboration. MUVEs contain tools that allow users to alter the terrain and to create 3D models. The environment is programmable. MUVEs 
are multimedia platform; video, sound, pictures animations can all be supported. Thus a rich set of educational resources can be brought together and accessed through a 3D virtual world client.

The participants of a MUVE are free to create new artefacts and engage in any form of social interaction. It is this freedom that makes MUVEs attractive when creating exploratory learning environments (Sturgeon et al, 2006).

Of the available virtual world environments Second Life has been the most widely used. It offers a good approximation to the real world and also offers flexibility to its users. (Loueiro, 2011).

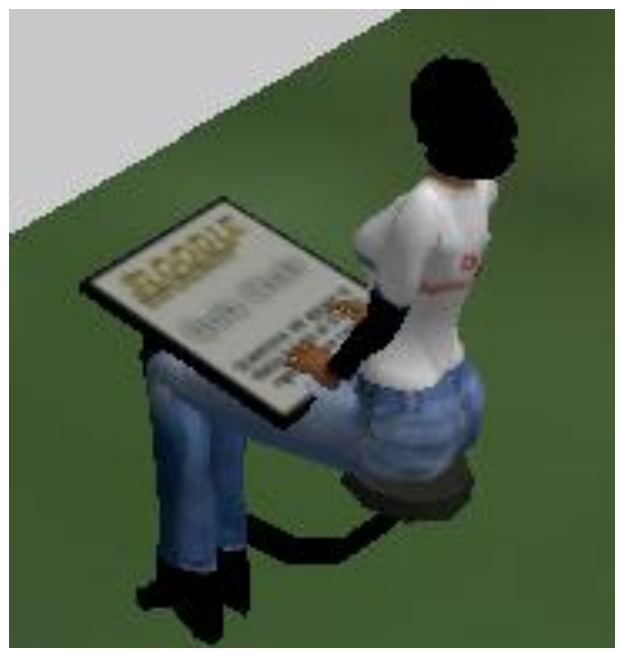

Figure 1: Sloodle Quiz Chair

Second Life is currently used within educational institutions as a platform for learning (Kemp, 2006) and prior to this time; it has been the most common virtual world technology in use in education. It was not originally designed for open educational use and as a result has significant social, economic and technical drawbacks when used for that purpose. These drawbacks include the commercial cost, limited programmability, restricted program resource usage, severely restricted backup, copy and sharing of content (including one's own), limited communication with facilities outside of the virtual world, the inappropriate presence of "adult content", age restrictions that can cut across higher education classes, and the difficulty of management of user ids and credit-bearing coursework (Allison et al, 2011).

OpenSim shares the same user interface as SL and clients are typically interoperable. However, OpenSim is open source simulator and can be used to support self-hosted virtual worlds with local administration and maintenance (Sturgeon et al,
2009). If an institution wants to run its own Virtual World service OpenSim offers an attractive option.

Developing, deploying and running a local virtual world service allows opportunities to improve support for content creation, application development, service provision and system development. These in turn allows the range of in world activities that are supported by the virtual world to be enriched.

OpenSim facilitates the sharing of resources through OpenSim archive (OAR) files. Through running a local virtual world service the full power of virtual worlds can be utilised. Administrative control opens the opportunity to enable powerful programming paradigms and enables more complex and powerful applications to be built.

Running a local service, offers the possibility of significantly reducing the marginal costs associated with the service. This in turn means that there is sufficient in world space to enable students to construct realistic virtual refugee camps. .

\subsection{Moodle and Sloodle}

Moodle is a Course Management System (CMS) with a set of tools built into an interface, which make the task of learning central. Using these tools, courses can be arranged by week, topic or social arrangement (Cole, 2007). Moodle offers three advantages amongst all CMS namely; it is open sourced, community based and its unique educational philosophy.

Sloodle is a plug-in for Moodle which came about as a result of a need to provide an additional set of tools to support learning and teaching in a virtual world. It aims to provide a means for effective learning, support and management within a 3D multi-user virtual environment (Livingstone, 2007).

The Sloodle application is integrated into Moodle so that a participant can be in-world and receive material directly from Moodle (Hodge, 2011). This helps avoid dependence on an ad hoc collection of third-party add-ons. It also enables educators to focus on teaching and the content of lessons rather that the process of content creation and having to learn the underlying language for content creation (Livingstone, 2007).

Some studies have suggested that the way in which learning objects are designed and the contexts in which they are situated are important in determining their educational value (Getchell et al, 2005). Sloodle has several in-built functionalities such as the administration of quizzes in virtual 
worlds, the submission of assignments by students, as well as a blogging and chat feature (Cohen, 2008). It combines with the Moodle CMS to create a new dimension in learning. This occurs through the configuration of a number of integration points which offer two way interactions between Moodle and Sloodle (Marmaridis, 2009). This integration is made possible by various Sloodle objects such as quiz chairs (Figure 1) linked to quizzes set up on Moodle, presenter objects for multimedia presentations (Figure 2) and polling tools which facilitate in-world voting (Figure 3 ).

In other to achieve the desired level of integration, the Sloodle system not only provides a mechanism for authenticating users between both systems, but it also maintains details of user identities as the users move from one system to another in the course of their normal learning interactions (Marmaridis, 2009). This process is known as registration or linking and it involves the linking of the OpenSim Avatar to the Moodle account through the Sloodle registration booth located in the VHD. In order to accomplish this, the Moodle site stores a list of Avatars it has interacted with and then associates each Avatar with a particular Moodle account.

\section{THE VHD}

The motivation for creating the VHD in a virtual world was based on recognition of the fact that virtual worlds provide an immersive and collaborative environment which could be used to realistically and safely simulate operational, moral and ethical dilemmas that humanitarian aid workers encounter in the field. These simulations allow users to develop key decision-making skills as they explore and encounter dilemmas. They can also reflect on the possible consequences of their choices, without the associated endangerment of human lives that would occur in a real world situation.

The key aim of developing the VHD was to create a virtual humanitarian disaster teaching and learning resource that would present students with some of the dilemmas faced by humanitarian aid workers responding to humanitarian emergencies. It also aims to use the power of virtual simulations to impart knowledge and learning in a way, which enhances classroom based teaching methods. Figure 4 depicts the structural layout of the VHD illustrating the relationship between its educational and technological components.

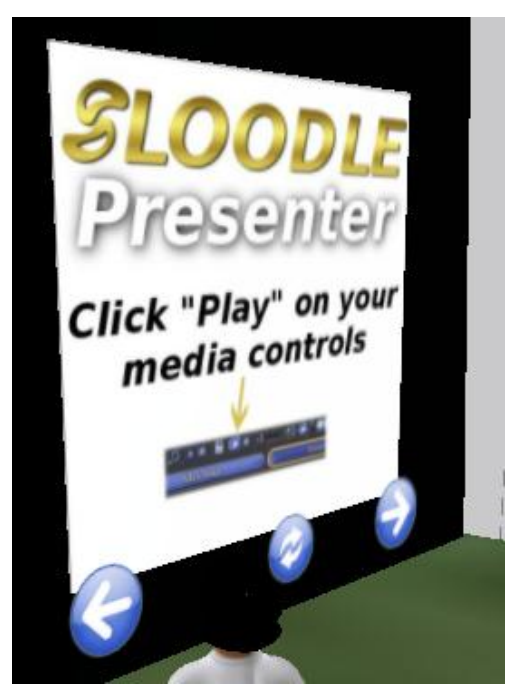

Figure 2: Sloodle Presenter.

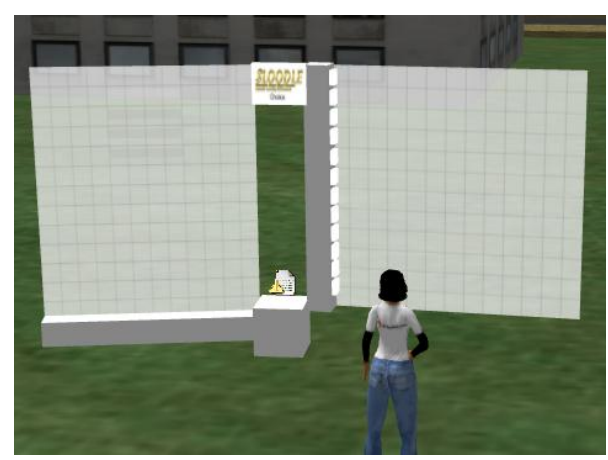

Figure 3: Sloodle Choice Tool.

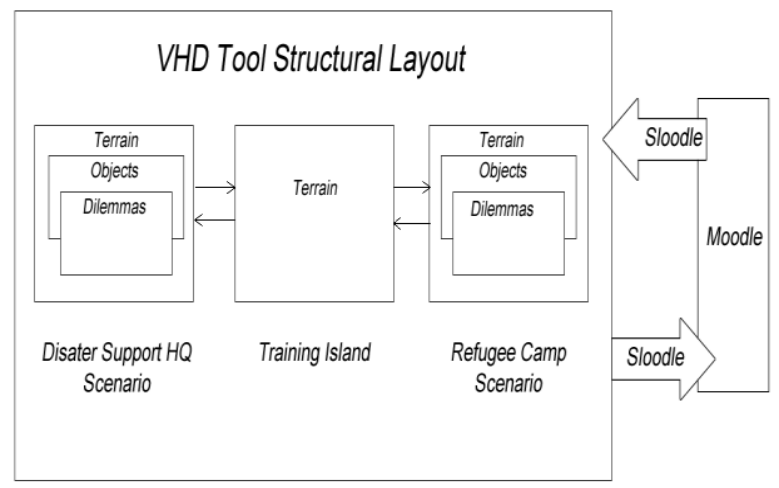

Figure 4: VHD Structural Layout.

\subsection{Functionality}

The operational dilemmas embedded within the VHD have been drawn from critical areas of activity for humanitarian aid agencies that include for 
example; geo-political relationships, legal/regulatory requirements, information management, logistical, human resource management and financial imperatives as well as the broader considerations related to the humanitarian imperative.

The tool provides the flexibility to drill down and explore an issue arising in any of these areas of activity in depth or to examine interconnections across all of these areas and the challenges and implications arising therefrom. It also allows a 3D reconstruction of relevant scenarios to be designed and built and enables participants to role-play in realistic scenarios in-world. Students will be briefed about their roles prior to the role-playing exercise and when in the environment of the VHD, they will be represented by avatars. Figure 5 shows a use case of the key actors of the VHD and the functional benefits derived by each actor. A user can be a student or an educator, with each role having its own specific benefits or sharing benefits with the other role.

The use of the VHD will be preceded by a briefing session with students in which the aims and nature of the exercise will be explained. Students will be invited to reflect upon and discuss the operational dilemmas and appropriate responses to the dilemmas. They will also be required to evaluate and discuss the implications arising from their decisions. Relevant academic literature will be drawn on at the de-briefing stage, to ground the discussion and to assist critical reflection on the part of the students.

\subsection{The Learning Scenarios}

There are two main generic scenarios depicted in the VHD based on dilemmas that a humanitarian aid worker would be most likely to encounter in the course of carrying out his or her duties.

- Scenario 1: Disaster Support Headquarters

- Scenario 2: Consideration of the internally displaced population affected by the disaster, the building of a refugee camp to accommodate the displaced population.

On the basis of these scenarios, the students are expected to undertake two main tasks:

- Walk through a total of 13 task dilemmas which have been built into the disaster support headquarters and refugee camp scenarios. The facilitators may add new dynamics or considerations based on the developing scenarios;

- Build an ideal refugee camp on the training island using objects in the inventory toolkit.

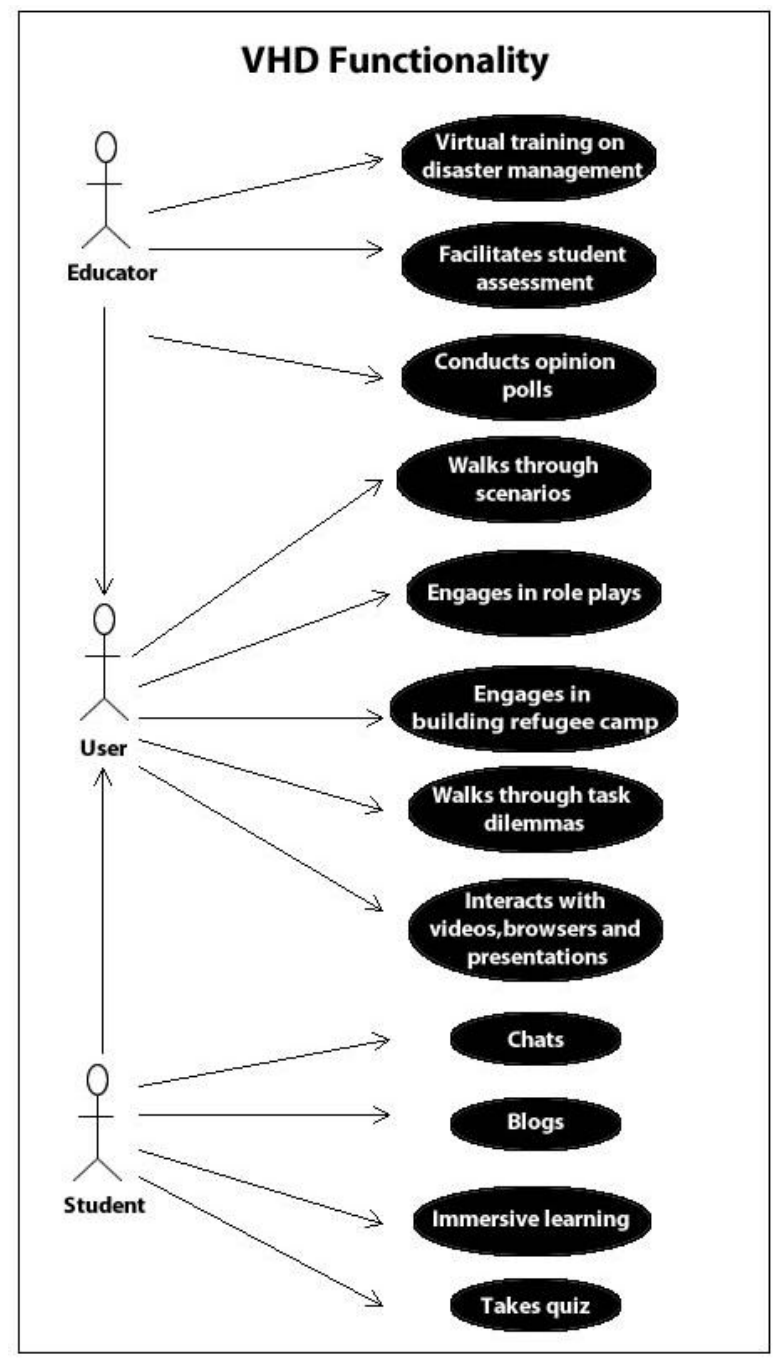

Figure 5: VHD Use Case.

\subsubsection{Disaster Support Headquarters}

Disaster Support Headquarters is the starting point of the VHD. The learning objective is to set the scene for the disaster by briefing students about their various roles. To achieve this, an organisational chart has been created. Job descriptions and roles of each key executive have been placed in a notecard and offer students the opportunity to understand the perspectives of the executives who are at the helm of affairs in a humanitarian aid agency. It is based on the premise that there are sometimes differing opinions between the frontline operational staff and headquarters staff whose interpretations may be more strategic. Each of these groups may often be unmindful of the conflicting priorities being confronted by the other. 


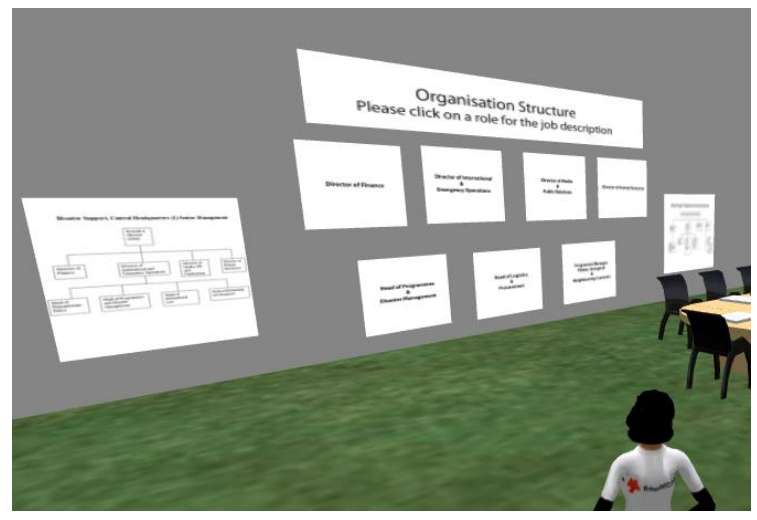

Figure 6: Organisation Structure

In order to accomplish the learning objective, the adopted strategy is to have students walk through some of the dilemmas they might encounter while in the field. These dilemmas have been chosen to examine key issues such as;

- The implications of a reduction in donated income over a period of time

- The legal and contractual agreements in place with suppliers and the sufficiency of such contracts

- Political concerns involving donor governments

- The hostilities and strained relationships which can arise between neighbouring communities in the aftermath of a humanitarian emergency, as well as the responsibility for management of refugee camps and competition for funding amongst the various agencies

- The security procedures within a humanitarian aid agency to protect its personnel

- The principle of 'do no harm' and the various ways in which it is manifested.

This strategy teaches students through an interactive process using notecards, which have been placed in objects in-world (Figure 7). When a student interacts with specific objects, a notecard appears which they can choose to either discard immediately after use or save for future reference. Each notecard contains details of a specific task dilemma designed to serve as a topic of discussion for students to resolve in groups at the briefing office (Figure 8). One such task dilemma, the personnel safety task dilemma, concerns the security procedures in place within an NGO operation and is intended to encourage discussion on how operations management can ensure that their personnel are protected as best possible, without compromising on their ability to perform their humanitarian work.

The supplier task dilemma examines a scenario occurring one week after the humanitarian emergency when it has become clear that the scale of the humanitarian emergency is such that will completely deplete existing stockpiles of blankets and a crucial protein-rich bar in the midst of the crisis. During this scenario, the suppliers have announced that they want to re-negotiate the price of further consignments. This is intended to prompt a discussion relating to the legal and contractual agreements in place with suppliers and the sufficiency of such contracts. Another medium used is in- world browsers, which have been configured to access specific websites relevant to the module. These sites include amongst others the International Federation of Red Cross and Red Crescent Societies (IFRC) website which provides an emergency items catalogue for disaster response teams and the World Food Programme Logistics Cluster site which provides logistics planning information for humanitarian aid agencies. The video of a humanitarian emergency news broadcast is also available in world to set the tone for the humanitarian emergency.

By adopting the foregoing strategy, we hope to achieve the following objectives:

- Developing the students' appreciation of how NGOs respond to disaster situations with regards to the relatively standard arrangements that will be in place in a particular NGO.

- Creating an appreciation of the issues that will emerge unexpectedly in the course of a disaster response exercise.

- Raising an awareness of key features in the humanitarian aid landscape of which they need to take account as they consider their responses to situations that arise in the course of a humanitarian aid mission.

- Allowing students to realise that choices that are made about how to deal with a particular situation will have implications and to try to follow through on this by anticipating what these may involve.

- Trying to achieve as much authenticity as possible within the limits of the VHD design.

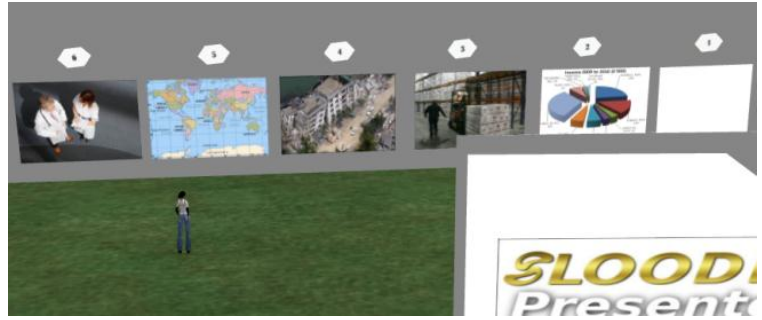

Figure 7: Task Dilemmas. 


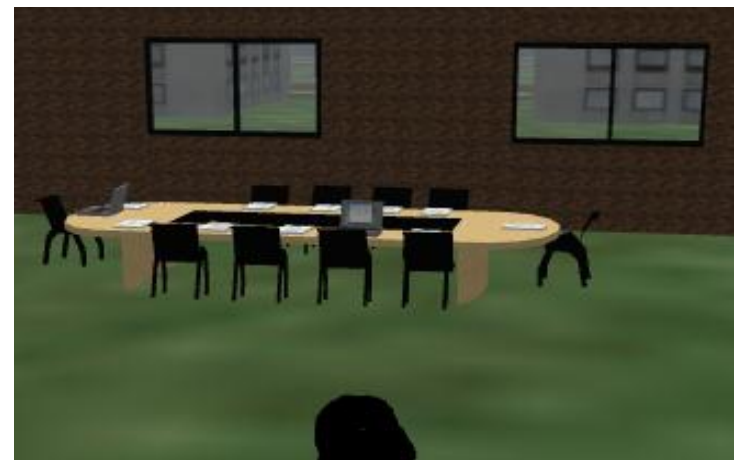

Figure 8: Disaster Support Briefing Office.

\subsubsection{Building a Refugee Camp}

An island has been created to allow students to build their own refugee camp. Prior to attempting this task, students are given a briefing sheet containing a prepared budget of the required human and material resources needed for the refugee camp. The aim here is to offer students the freedom and flexibility to work together in teams to build a refugee camp using the objects contained in the inventory toolkit while using the supplied budget as guidance.

The resources contained in the list have been placed inside a VHD inventory toolkit. In addition to these objects, other items have been included to test the student's discretionary abilities to differentiate between the useful and unnecessary items.

The human and material resources contained in the toolkit can be grouped into the following categories:

Table 1: Inventory Toolkit Items

\begin{tabular}{|c|c|}
\hline Category & Item \\
\hline Shelter & $\begin{array}{c}\text { Family and personnel } \\
\text { tents, blankets, } \\
\text { mattresses, etc. }\end{array}$ \\
\hline Security & $\begin{array}{c}\text { Perimeter fence, security } \\
\text { gate, flood lights, aerial } \\
\text { guard tower, etc. }\end{array}$ \\
\hline Food & $\begin{array}{c}\text { Bottled water, bags of } \\
\text { rice, wheat flour, etc. }\end{array}$ \\
\hline Medical & $\begin{array}{c}\text { Ambulances, medical } \\
\text { tents, medical supplies, } \\
\text { etc. }\end{array}$ \\
\hline Sanitation & Latrines and bathrooms \\
\hline Miscellaneous items & $\begin{array}{c}\text { Furniture, laptop } \\
\text { computers, satellite } \\
\text { phone equipment, etc. }\end{array}$ \\
\hline
\end{tabular}

These objects are ready to be positioned in the refugee camp. Throughout this process students are confronted with a range of issues such as the correct camp layout; specifically the proximity of the tents to one another, sanitation issues such as the number of families required to share latrines and bathrooms, security details related to the level of illumination through floodlights required within the camp at night. Other issues include the medical needs of the camp residents particularly the number of ambulances and medical tents required (Sphere Project, 2011).

After completion of the task, the students will visit the reference refugee camp to compare their work against it.

\subsubsection{Reference Refugee Camp}

The refugee camp (Figure 9) is a scaled down model of a real camp set up in the aftermath of a disaster. Efforts were made to be as realistic as possible in the representation, to this end; careful research was conducted into the specific standards, which are to be adhered to and the required human and material resources needed to maintain it.

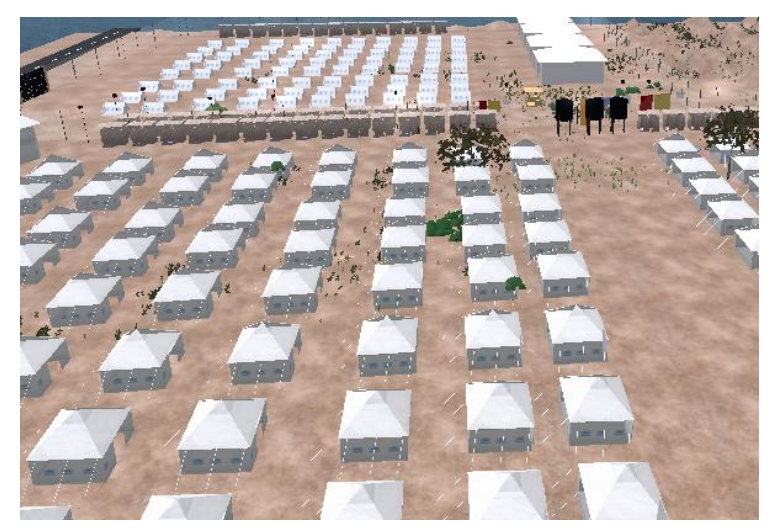

Figure 9: Aerial View of Completed Refugee Camp.

Prior to setting up the refugee camp, its layout was pre-established (Figure 10) based on the recommendations from the Office of the United Nations High Commissioner for Refugees (UNHCR) which provides specific guidelines and standards that refugee camps must conform with. These guidelines specify the minimum size of land on which a refugee camp should be built. For instance a camp of 20,000 people should be at least 900,000 square metres in size. It also stipulates the distance between living quarters, the number of individuals who may share a tent and the distance of latrines, water sources and showers from the living quarters. 


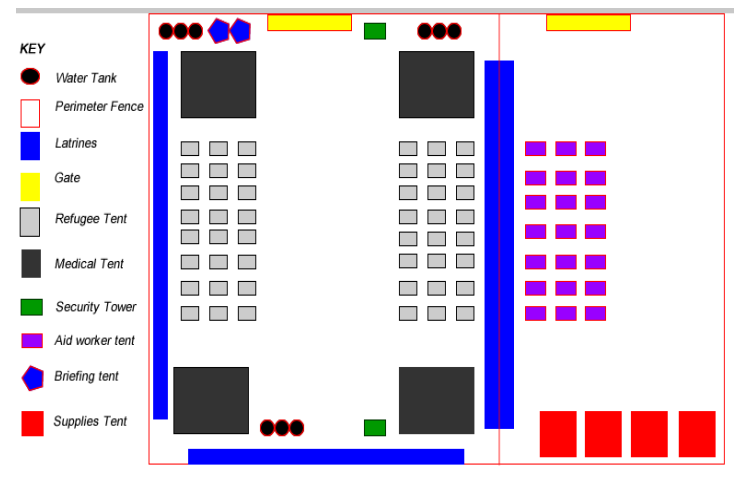

Figure 10: Refugee Camp Layout.

Following the research, a detailed budget was also prepared containing the requirements for a refugee camp that would accommodate 15,000 individuals. The budget contained details of costs and quantities of required human and material resources to meet security, health and other needs.

In accordance with the specifications of the budget, replicas of real world objects were created they include: food items (Figure 11), medical supplies (Figure 12) and basic items such as latrines.

The refugee camp also serves the purpose of providing a setting for walking through some of the task dilemmas. Some of these task dilemmas include the following:

- Deciding on the best way to handle unsolicited donations

- Identifying and selecting recipients of aid as well as deciding on distribution methods.

- The various moral and ethical issues the field workers sometimes encounter based on the principle of 'do no harm'.

To sum it up, the learning process of the VHD begins when students arrive at the disaster support headquarters briefing room where the scene is set for the disaster, students are then briefed about their roles, after the briefing, the various groups are assigned to different tasks involving the walk through of the task dilemmas and the creation of the refugee camp. After the creation of the camp, there is a review where students compare the newly built camp with the reference.

\section{EVALUATION}

At the time of writing evaluation work on the VHD is ongoing. So far the VHD has been evaluated by small groups of students for educational value and the educational benefits. Domain experts have evaluated the ability of the VHD to address real world issues. Systems aspects, such as number of concurrent users supported have also been tested. A brief explanation of each feature evaluated follows:

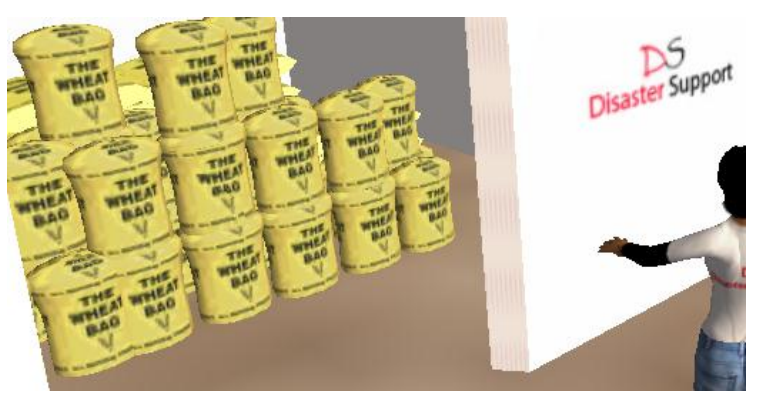

Figure 11: Food Supplies.

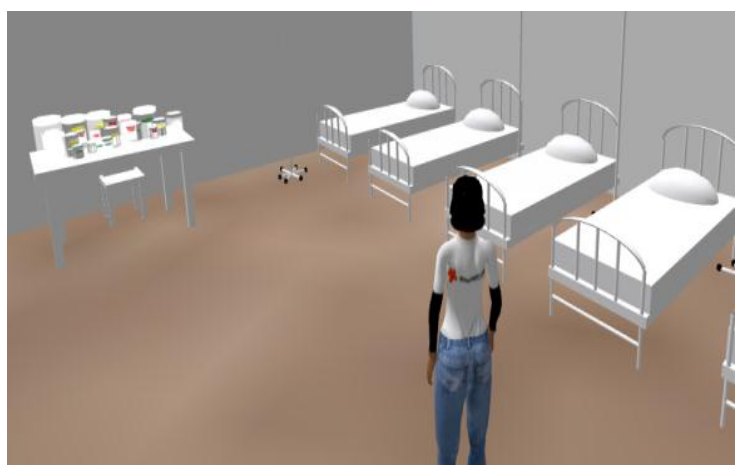

Figure 12: Medical Tent in the Refugee Camp.

- The scenarios were evaluated to ensure that the end to end functioning of the elements of the VHD was in order. The users were required to put themselves in the shoes of the stakeholders, such as donors, local authorities, DS central HQ and think through the real world dilemmas which are presented in the VHD. It was also aimed at helping users to explore how the VHD resource will function in the hands of a student user with the purpose of finding any existing short comings.

- A usability evaluation was performed to establish the user's ability to learn to use the resource and how convenient it was to use and understand it as well as its level of attractiveness.

- Performance evaluations were carried out to determine the effectiveness of the resource with regards to response times involved while interacting with objects. The purpose of the particular evaluation was to ensure that the VHD met with minimum performance criteria, 
and to identify which parts caused overall negative performance.

- Interoperability evaluations were aimed at determining the capability of the OpenSim software to interact with the Moodle and Sloodle software components with minimal difficulty.

On the basis of the above evaluation focus, the following specific features of the VHD were evaluated and formed the basis of the questionnaire administered:

- Ease of rezzing the VHD inventory toolkit objects in-world;

- Ability of the user's Avatar to register on the Moodle site from the in-world registration booth;

- $\quad$ Ease of use of the Second Life viewer versus other viewers such as Hippo, Imprudence and Meerkat;

- Functionality of audio and video media in world;

- Ability to browse the internet in-world;

- Ease of retrieving Moodle quizzes via the Sloodle quiz chairs;

- Accessibility of multimedia presentations via the Sloodle presenter object;

- The ease of walking through the various dilemmas.

The following evaluation comments were received from domain experts:

I was absolutely overwhelmed by what you had created, its very impressive.

I think it would add a great deal of value to have someone as the dungeon master. Students are going to have questions, some may be pertinent others may

not. For example, knowing the ratio of men to women will influence the number of latrines. Other questions may crop up and having someone with a bit of experience providing answers would help fill in the gaps.

As far as the actual camp site. I think, if possible, a river should be added. This would add a great deal of technical complexity that would engage students more. For example, where do you place the latrines, upstream or downstream? What about wash points? How close should the tents go to the river taking into consideration potential flooding?

These comments will be taken onboard and incorporated in the next phase of development.
On the basis of the evaluation carried out, the following feedback was received from test users who were required to walk through the questionnaire evaluating each of the VHD features in turn and provide feedback. The results of the evaluation are summarised in the table below:

Table 2: VHD Evaluation

\begin{tabular}{|c|l|}
\hline Feature & \multicolumn{1}{c|}{ Result } \\
\hline $\begin{array}{c}\text { Viewer } \\
\text { Compatibility }\end{array}$ & $\begin{array}{l}\text { The Second Life viewer 2, } \\
\text { Imprudence and Hippo viewers } \\
\text { were evaluated. The Second Life } \\
\text { viewer 2 was found to be the most } \\
\text { compatible and technologically } \\
\text { advanced of the viewers tested as } \\
\text { it utilizes the 'media on prim' } \\
\text { technology, which makes it } \\
\text { possible to place videos in prims. }\end{array}$ \\
\hline Usability & $\begin{array}{l}\text { Users required some time and } \\
\text { guidance become familiar with } \\
\text { how to navigate the resource. }\end{array}$ \\
\hline Scenarios & $\begin{array}{l}\text { Users considered the dilemmas as } \\
\text { explicit enough and adequately } \\
\text { representative of the scenarios. }\end{array}$ \\
\hline Functionality & $\begin{array}{l}\text { Users also regarded the resource } \\
\text { as successful in simulating the } \\
\text { real world. }\end{array}$ \\
\hline
\end{tabular}

\section{CONCLUSION}

We have been able to ascertain the success of virtual worlds in humanitarian aid training and from evaluation of the resource, we can see that virtual worlds have the potential to change the way in which training programmes are delivered.

The VHD could be further enhanced to incorporate a wider range of scenarios and by integrating some automation in its environment. Both enhancements are discussed in more detail below.

The VHD has incorporated scenarios and dilemmas related to activities critical to NGOS ranging from logistics, geo-political relationships, legal and regulatory requirements, information management imperatives, logistical imperatives, human resource management imperatives, and financial imperatives. The areas covered here are by no means exhaustive and there are opportunities for further work based on trends and evolving issues in the humanitarian aid scene. As new developments occur, they can be incorporated into the resource 
ensuring the continued relevance of the VHD resource.

The VHD is currently limited in its automation, but has the potential to enhance the user experience further, as well as the sense of realism derived from it by integrating specific automated features. This could be achieved by; specialised animations to automate the actions of avatars, the use of particles to simulate effects like changes in weather and scripting of objects such as helicopters and motor vehicles. Automated Heads up Displays (HUDs) could be used to provide direction within the virtual world. The process of disbursing budget items could also be automated in order to help monitor on-going costs.

Largely, it is anticipated that the VHD has the potential for wider applications in the 'real world. Not only for the use of humanitarian aid workers, but also in further undergraduate, postgraduate, and executive level courses that explore complex and challenging operational dilemmas and decision making. The VHD creation process and evaluation results can be drawn upon and applied by academics and professionals across a range of disciplines.

\section{ACKNOWLEDGEMENTS}

The project received start-up funding in the form of a University of St Andrews FILTA award.

\section{REFERENCES}

Allison, C., Miller, A., Sturgeon, T., Perera, I., McCaffrey, J. 2011. The Third Dimension in Open Learning. $41^{\text {st }}$ ASEE/IEEE Frontiers in Education Conference.

Allison, C., Miller, A., Sturgeon, T., Nicoll, J.R., Perera, I. 2010. Educationally Enhanced Virtual Worlds. 40th IEEE Frontiers in Education Conference, 2010. FIE '10. Washington: IEEE.

Beristain C.M., 2006. Humanitarian aid work: a critical approach. University of Pennsylvania Press.

Cahill, K.M., 2003. Basics of international humanitarian missions. Fordham University Press.

Cohen, E., 2008. Setting Knowledge Free. The Journal of Issues in Informing Science and Information Technology, 5, p.132.

Cole, J.R., Foster, H. 2007. Using Moodle: Teaching with the Popular Open Source Course Management System (Google e-book). O'Reilly Media Inc. Pg.5.

D'Souza, F., 2007. Who is a refugee? Definitions and assistance. Disasters, 5(3), pp.173-175.

DFID, 2011. Humanitarian Emergency Response Review.
Getchell, K., A. Miller, and C. Allison. 2005 A TCP Learning Environment. In 6th Annual Conference of the Subject Centre for Information and Computer Sciences. York: Higher Education Academy.

Grondstedt, A., 2008. Training in virtual worlds. American Society for training and development, 25(0803).

Heiphetz, A., Woodill, G., 2010. Training and collaboration with virtual worlds, McGraw Hill.

Hodge, E., Collins, S. Giordano, T., 2011. The virtual worlds handbook: how to use Second Life and other $3 D$ virtual environments.

International Federation of Red Cross and Red Crescent Societies. 2011 What is a Disaster? http://www.ifrc.org/en/what-we-do/disastermanagement/about-disasters/what-is-a-disaster/

Kemp, J., Livingstone, D., 2006. Putting a Second Life "Metaverse" Skin on Learning Management Systems. In Proceedings of the Second Life Education Workshop at the Second Life Community Convention San Francisco. pp. 13-18.

Lemons, H.', 1957. Physical Characteristics of Disasters: Historical and Statistical Review. Annals of the American Academy of Political and Social Science., 309, pp.1-14.

Livingstone, D., 2007. The European Conference on Games Based Learning. In Learning Support in Multi -User Virtual Environments. Academic Conferences Limited, pp. 185-191.

Loueiro, A., Bettencourt, T., 2011. The Extended Classroom: meeting students' needs using a virtual environment. Procedia Social and Behavioural Sciences 15 (2011) 2667-2672, 15.

Marmaridis, I., Griffith, S., 2009. Information Systems: Modelling, Development, and Integration: Third International United Information Systems Conference, UNISCON. In Metaverse services: extensible learning with mediated teleporting into $3 D$ environments. Springer, pp. 252-260.

Perera, I., Allison, C., Nicoll,R., Sturgeon, T. 2009 Towards Successful 3D Virtual Learning- A Case Study on Teaching Human Computer Interaction. 4th International Conference for Internet Technology and Secured Transactions. London: IEEE Press.

Sphere Project, 2011. Humanitarian Charter and Minimum Standards in Humanitarian Response. Belmont Press Limited.

Sturgeon, T., C. Allison, and A. Miller. 2006 A WiFi Virtual Laboratory. in 7th Annual Conference of the Higher Education Academy Subject Centre for Information and Computer Sciences. Dublin, Ireland: HE Academy.

Sturgeon, T., C. Allison and A. Miller. Exploring 802.11: real learning in a virtual world. in 39th IEEE Frontiers in Education Conference, 2009. FIE '09.2009: IEEE

UNHCR 2011 Protection Training Manual for European Border and Entry Officials. p.6. 